\title{
El proceso del turismo residencial. Análisis sociopolítico de los discursos públicos desde una perspectiva cualitativa
}

\author{
AlejANDRO MANTECÓN \\ Universidad de Alicante \\ alejandro.mantecon@ua.es
}

Recibido: 10.12 .2009

Aceptado: 09.12.2010

\section{INTRODUCCIÓN}

Los movimientos migratorios protagonizados desde los años 70 por centro y noreuropeos que se desplazan hacia las regiones mediterráneas con el fin de reorientar sus vidas hacia la práctica cotidiana de actividades más vinculadas a la esfera del ocio que al ámbito productivo, y su articulación en el sur de España con los flujos turístico-residenciales internacionales (O'Reilly 2003, 2007), representan uno de los fenómenos más singulares de integración informal de la sociedad europea (Schriewer y García 2005). La creciente complejidad de estas formas de movilidad encuentra su contexto en la expansión (y parcial democratización) de algunos de los efectos de la globalización, como la mayor facilidad para desarrollar proyectos biográficos transnacionales (Jiménez 2010). A su vez, las nuevas estrategias residenciales, y su concreción en estilos de vida en los que las actitudes y comportamientos turísticos se confunden con los de los procesos migratorios, se han imbricado en la lógica económica de los mercados inmobiliarios nacionales e internacionales, lo que, en última instancia, ha provocado profundos cambios en las regiones receptoras.

En las siguientes páginas se analiza el contexto ideológico de las sociedades receptoras en el que este complicado proceso tiene lugar. Para ello, se parte de una breve aproximación socio-histórica a la realidad turística española y, específicamente, a la doble naturaleza del proceso turístico-residencial. Seguidamente, se especifican los objetivos concretos del estudio y se explica y razona el enfoque metodológico cualitativo empleado para recoger la información. Des- 
pués se detalla y justifica la estrategia elegida para analizar los discursos identificados (en este caso, la teoría del discurso propuesta por Ernesto Laclau). Tras el análisis propiamente dicho, en el que se examinan las dos posiciones discursivas extremas, se presentan las conclusiones.

\section{TURISMO Y CAMBIO SOCIAL EN ESPAÑA: UNA BREVE APROXIMACIÓN}

A mitad de la década de los años 50 la autarquía franquista se mostró insostenible y los tecnócratas del Opus Dei tomaron las riendas de la gestión económica, a la que intentaron dar un giro aperturista (García de Cortázar y González Vesga 1994). Las medidas modernizadoras se ordenaron en torno al «Plan de Estabilización» de 1959. Las repercusiones provocadas por los cambios en la dirección político-económica son complejas. No obstante, resulta importante indicar que los gestores inspiradores del «Plan» situaron al turismo como pilar de la modernización española, dando un impulso crucial a un proceso de desarrollo turístico que venía fraguándose desde hacía décadas (García de Cortázar y González Vesga 1994; Pack 2006). De este modo, España se convirtió en uno de los destinos vacacionales preferidos por las clases medias de los países europeos más avanzados. La demanda turística es muy elástica respecto a la renta por lo que el mayor bienestar de los europeos, inmersos en un ciclo de expansión socioeconómica, desembocó en un alto consumo de ocio vacacional. Millones de europeos escogieron las costas mediterráneas españolas atraídos por sus bondades climatológicas, los bajos precios y un ambiente sociopolítico que trasmitía seguridad, aunque éste lo garantizara el franquismo. La imagen de las costas mediterráneas como un espacio idílico caracterizado por sus playas y la luz del sol se repitió insistentemente. Al mismo tiempo, un millón de trabajadores emigraron entre 1960 y 1970, a través de los conductos legales, para trabajar en las fábricas de Francia, Alemania, Suiza, Bélgica y Holanda, aunque los que salieron extraoficialmente casi superaron esa cifra (Carr 1980). Los envíos de divisas de los emigrantes, junto a los ingresos obtenidos gracias a la explosión del turismo de masas, financiaron el progreso industrial español de los años 60, que pasó a conocerse como la «década del milagro» (García de Cortázar y González Vesga 1994).

Los ingresos obtenidos a través del turismo compensaron el saldo negativo de las demás partidas de la Balanza de servicios y cubrieron una parte esencial del déficit de la Balanza Comercial. El turismo se configuró así como el salvador del equilibrio económico (Roldán López y García Delgado 1973). La canalización del desarrollo económico español a través de la industria turística llegó a constituirse en un caso paradigmático observado con atención por los gobiernos de otros países. 


\section{LAS DOS CARAS DEL PROCESO TURÍSTICO-RESIDENCIAL}

El beneficio evidente que el desarrollo turístico español ha supuesto para la economía nacional, y para la recuperación del patrimonio cultural de muchas ciudades, se ve acompañado por otros procesos entre los que destacan: 1) los impactos ambientales derivados de la actividad urbanística asociada al turismo, sobre todo: la ocupación urbanística de un territorio limitado, la sobreexplotación de unos recursos hídricos escasos y la destrucción irreparable de entornos naturales de incalculable riqueza (Vera e Ivars 2003); y 2) las transformaciones en las estructuras sociodemográficas de muchas localidades a partir de la doble inmigración de, por un lado, mano de obra joven atraída por el mercado laboral y, por otro, los flujos de población protagonizados por turistas y migrantes de edad avanzada que fijan su residencia durante varios meses al año en el nuevo enclave turístico (Casado 1999).

El primero de los procesos citados tiene que ver con una de las dos caras del turismo residencial: la que muestra un modelo de desarrollo basado en la producción de suelo urbano para la construcción de viviendas destinadas inicialmente a un uso no principal. Se trata de un sistema económico sustentado en la actividad del sector inmobiliario y de la industria de la construcción que ha hecho pasar por desarrollo turístico lo que frecuentemente solo ha sido crecimiento de la edificación. Si se consultan las estadísticas publicadas por la Tesorería General de la Seguridad Social referentes a la provincia de Alicante se aprecia que, con la excepción de Benidorm, en los municipios turísticos más significativos el porcentaje de empresas y empleados ligados al sector inmobiliario y de la construcción es considerablemente mayor que el de las empresas y empleados vinculados al sector hostelero (OOA 2006). La naturaleza inmobiliaria del proceso también puede advertirse al observar la presión urbanística a la que están sometidos la mayoría de los municipios que conforman las regiones mediterráneas. La ocupación masiva de la costa iniciada en la década de los años 60 se ha intensificado durante la etapa democrática, tanto bajo el mandato de gobiernos de derechas como de izquierdas. En 1987 estaba construida el $22 \%$ de la franja mediterránea formada por los dos kilómetros más próximos al mar, en el año 2005 ese porcentaje llegaba al 34\%. La Comunidad Valenciana ya tiene ocupado casi el $40 \%$ de esa franja costera y cada año aumentan el número de municipios con más de la mitad de su suelo urbanizado o calificado como urbanizable (OSE 2006). Otro hecho ilustrativo es el desajuste existente entre las plazas de alojamiento hotelero y las plazas de viviendas secundarias y vacías. Al respecto, los datos publicados por el INE y la Agencia Valenciana de Turismo indican que en la mayoría de los municipios del litoral mediterráneo, sobre todo del alicantino, el porcentaje de plazas extrahoteleras (fundamentalmente en viviendas secundarias) sobre el total de la oferta de alojamiento turístico se halla por encima del $90 \%$. Por lo tanto, no debe extrañar que, tal y como se recogía en el censo de 2001, el porcentaje de viviendas secundarias sobre el total de viviendas su- 
pere ampliamente el $50 \%$ en los municipios más consolidados (Mantecón 2008a,b). Las estimaciones sobre el número de plazas en viviendas privadas destinadas al mercado turístico oscilan entre los 12 y los 21 millones para todo el país, aunque la mayor parte se localizan en el litoral mediterráneo. El amplio margen existente entre la cifra más baja y la más alta de la estimación se debe a la situación de subregistro en la que se hallan miles de viviendas. Si se sabe que la oferta de plazas en establecimientos reglados se acerca a los 3 millones, ello quiere decir que la dimensión real de la oferta de alojamiento turístico en viviendas no principales es entre 4 y 7 veces mayor (Requejo 2007). No obstante, los datos de alojamiento reglado son suficientemente clarificadores: el 75\% de las pernoctaciones realizadas en la Comunidad Valenciana durante 2006 se hicieron en viviendas privadas (27\% en viviendas propias, $19 \%$ en viviendas alquiladas y $29 \%$ en viviendas de familiares o amigos), frente a un 18\% en hoteles y un $7 \%$ en otros tipos (OVV 2007). Una buena aproximación al análisis del caso español desde esta perspectiva puede hallarse en los trabajos de del Pino 2003, 2009; Gaviria 1976; Jurdao 1979; Mazón 2001, 2006; Monfort e Ivars 2001; Pedro 2006; Vera 1987, 2005; Vera e Ivars 2003.

El segundo de los procesos referidos hace alusión a la otra cara del turismo residencial: la que oculta un complejo sistema en el que convergen diferentes formas de movilidad residencial, en las que los límites entre el turismo y la migración residencial se tornan borrosos (la explicación de estas dinámicas en las regiones mediterráneas puede encontrarse en Casado 1999, 2006; Gustafson 2001, 2008, 2009; Huber y O'Reilly 2004; Huete 2009; King 2002; King et al. 2000; Rodríguez et al. 2004). Dos grupos dan forma a los tipos de movilidad residencial por motivos de ocio más significativos en estas regiones. Por un lado, los turistas que en vacaciones se trasladan a un apartamento localizado en un espacio caracterizado por las experiencias de ocio. Cuando Callejo, Gutiérrez y Viedma (2004) estudian el turismo residencial analizan las dinámicas de estas personas. Evidentemente, la naturaleza de sus estancias es turística, igual que lo es la de quienes se hospedan en un hotel, un hostal o un camping. Por otro lado, puede reconocerse otro grupo más complejo. Después de varios años investigando las formas de vida de los ciudadanos británicos en la Costa del Sol, Karen O'Reilly (2000, 2003, 2007) identifica: 1) un grupo principal de migrantes retirados, y 2) dos grupos minoritarios de migrantes empresariales (propietarios de pequeños negocios orientados a los ciudadanos noreuropeos) y de migrantes económicamente activos (personas con auténticos estilos de vida transnacionales que realizan su trabajo desde la distancia o realizando viajes frecuentes entre sus países y España). El grupo mayoritario, el de los migrantes retirados, agrupa una variedad de tipos en los que se confunden los rasgos turísticos con los migratorios. Ello ha llevado a esta autora a emplear en sus últimos trabajos la expresión «lifestyle migration», como herramienta analítica con la que hacer referencia a esta compleja realidad (O'Reilly y Benson 2009). Este entramado social queda enmarcado en una situación de subregistro adminis-

EMPIRIA. Revista de Metodología de Ciencias Sociales. N. ${ }^{\circ}$ 21, enero-junio, 2011, pp. 17-38. ISSN: 1139-5737 
trativo de la población, lo que genera problemas a las autoridades municipales para justificar debidamente el coste de la implantación de los recursos humanos e infraestructuras con los que garantizar el suministro energético, la recogida de basuras, el mantenimiento de las calles, el transporte público, etc. (Huete 2009).

\section{OBJETIVOS}

Desde enfoques teóricos y metodológicos diferentes, la mayoría de los trabajos citados estudian aspectos relacionados con las repercusiones socioeconómicas, urbanísticas, geoambientales y sociodemográficas vinculadas a la evolución del proceso turístico-residencial. Al respecto, y en el ámbito de la sociología española, resulta ilustrativo el artículo reciente de García et al. (2010), en el que la investigación cualitativa mediante dinámicas de grupo se pone al servicio de la elaboración de mapas conceptuales con los que se identifican los impactos provocados mediante la actividad turístico-residencial y las causas que los motivan. El estudio de las dimensiones culturales del proceso (estilos de vida, significados, expectativas, interacción social) han sido menos estudiadas, si bien algunas aportaciones esenciales han sido realizadas por O'Reilly (ver especialmente su libro de 2000), así como los textos de Gustafson (2001, 2008), King et al. (2000) o Schriewer y García (2005). Más escasos son los análisis que se interesan por las repercusiones culturales en las sociedades receptoras (Barke 1999) y, entre estos, son excepcionales las publicaciones que desarrollan un enfoque orientado a la comprensión de los aspectos ideológicos y a la construcción de significados y discursos sociales (puede citarse Mantecón 2008a,b).

Aquí se realiza una aportación al análisis de las dimensiones ideológicas que rodean a este particular proceso de modernización, pues su explicación puede ofrecer claves sociológicas que ayuden a entender la intensidad de su evolución. Específicamente, se identifican y analizan, desde una perspectiva cualitativa, las características de las principales posiciones ideológicas que actualmente compiten por conseguir una posición de hegemonía en el sistema turístico-residencial de las sociedades mediterráneas. El campo discursivo es analizado desde la perspectiva de los discursos posicionados en los dos extremos del espectro ideológico. En las publicaciones de Mantecón (2008a,b) se presenta un detallado análisis de los discursos de la sociedad receptora acerca del proceso turístico-residencial, aunque la atención analítica y las conclusiones obtenidas se fijan en las posiciones discursivas intermedias. Ello ofrece hallazgos interesantes, como el reconocimiento de un significativo contexto de legitimación social, pero al dejar en un segundo plano analítico las posiciones discursivas que ocupan los extremos del espectro ideológico también se pierden aspectos importantes en la comprensión del proceso. Solventar ese déficit analítico es la razón que impulsa la redacción de este artículo.

EMPIRIA. Revista de Metodología de Ciencias Sociales. N. ${ }^{\circ}$ 21, enero-junio, 2011, pp. 17-38. ISSN: $1139-5737$ 
El propósito de la investigación es, en definitiva, comprender el modo en el que la modernización turístico-residencial ha sido explicada por la sociedad anfitriona. Se trata de analizar la lógica de actuación de los discursos producidos por cuatro grupos clave de poder en el ámbito local: las elites políticas, los principales agentes económicos implicados, los expertos y la ciudadanía. La selección de estos grupos se basa en la aplicación a la planificación turística de la teoría de las partes interesadas (Sautter y Leisen 1999).

\section{METODOLOGíA}

Se eligió la entrevista en profundidad como la técnica apropiada para recabar la información de los políticos, los empresarios y los expertos. El grupo de discusión se empleó para recoger la información de la ciudadanía. Su utilización en este estudio viene dada por su idoneidad para identificar los discursos producidos por los ciudadanos, a partir de la presunción de que cuando un individuo no es experto en un tema por el que está afectado necesita compartir sus inquietudes con otras personas en su misma situación para terminar de consolidar una opinión sobre el asunto en cuestión (Marshall y Rossman 1999). Las entrevistas y los grupos se aplicaron utilizando un guión semi-estructurado con cuestiones relacionadas con la situación medioambiental, las actividades económicas, las relaciones entre los españoles residentes permanentes y el resto de grupos, la definición y valoración del modelo turístico y las transformaciones sociales. Las preguntas se formularon en un orden que permitiera identificar y analizar las secuencias narrativas que estructuran los discursos. El trabajo de campo se llevó a cabo en 5 municipios costeros de la provincia de Alicante, tipológicamente representativos del desarrollo turístico ligado a la intensa actividad inmobiliaria que tiene lugar en el Mediterráneo (Denia, Altea, Benidorm, Santa Pola y Torrevieja), seleccionados por ser los de mayor peso demográfico y con mayor número de viviendas secundarias registradas en la costa alicantina. El conjunto de las 37 entrevistas y los 6 grupos de discusión se completaron en 2006. El número de entrevistados se decidió en base al criterio de saturación discursiva de las categorías temáticas exploradas para cada uno de los grupos de actores sociales. La distribución de los entrevistados se recoge en el cuadro 1 . 
Cuadro 1. Distribución del total de los 71 entrevistados

\begin{tabular}{|l|l|}
\hline Actor social & Características \\
\hline Élites políticas & $\begin{array}{l}15 \text { entrevistas en profundidad a concejales de todos los partidos políticos } \\
\text { con responsabilidades en gestión turística y representación en los ayunta- } \\
\text { mientos de los municipios seleccionados }\end{array}$ \\
\hline Élites & $\begin{array}{l}9 \text { entrevistas en profundidad (4 a presidentes de asociaciones de hostelería } \\
\text { y comercio y 5 a empresarios promotores inmobiliarios que tienen como } \\
\text { principal ámbito de acción las regiones que se asoman al Mediterráneo) }\end{array}$ \\
\hline Expertos & $\begin{array}{l}13 \text { entrevistas en profundidad (5 a profesores universitarios con reconocida } \\
\text { experiencia en la investigación del proceso turístico-residencial en las re- } \\
\text { giones mediterráneas españolas y } 8 \text { a técnicos municipales de los ayunta- } \\
\text { mientos con responsabilidades en la gestión turística) }\end{array}$ \\
\hline $\begin{array}{l}\text { Ciudadanía } \\
\text { activa }\end{array}$ & $\begin{array}{l}\text { Se realizaron } 6 \text { grupos de discusión en los que participaron 34 personas, con } \\
\text { las que se pretendía recoger y representar los discursos de la ciudadanía. Sin } \\
\text { embargo, se ha considerado que el hecho de decidirse a participar en los } \\
\text { grupos ya da cuenta de que se ha tratado con personas que tienen una opi- } \\
\text { nión formada acerca de los temas que afectan a sus municipios y un interés } \\
\text { evidente por debatir sobre ellos. Aunque no eran miembros de organiza- } \\
\text { ciones políticas o económicas relevantes (pues eran maestros, amas de } \\
\text { casa, funcionarios, jubilados, estudiantes, propietarios de un pequeño ne- } \\
\text { gocio, etc.), sí que resultó que muchos formaban parte, o lo habían hecho en } \\
\text { el pasado, de diferentes asociaciones ciudadanas. La expresión "ciudadanía } \\
\text { activa" se inspira en la expresión similar "sociedad activa", acuñada por } \\
\text { Amitai Etzioni en su libro The Active Society (1968), donde proponía una } \\
\text { política de consenso entre las elites técnicas y las comunidades ciudadanas } \\
\text { autoconscientes y comprometidas con sus objetivos }\end{array}$ \\
\hline
\end{tabular}

Después de transcribir la información se procedió a la codificación de datos textuales. En una primera fase analítica cada uno de los códigos que se identificaba era agrupado en familias de códigos, y a continuación cada familia se asociaba con las secciones temáticas antes indicadas: «economía», «medio ambiente», «interacción social», «modelo turístico» y «cambio social» para, en una segunda fase analítica, reclasificar el material reunido asociando ideas y, al final, descubrir líneas discursivas y posicionamientos ideológicos (Sandelowski 1995). Los principales hallazgos de esta segunda fase de análisis se presentan en las siguientes páginas a la luz de la teoría del discurso elaborada por Ernesto Laclau. Se advierte que los resultados y las conclusiones obtenidas tienen la pretensión de explorar la estructura discursiva de unos posicionamientos ideológicos, pero, como ocurre en la investigación cualitativa, no hay intención alguna de realizar extrapolaciones o generalizaciones. 


\section{PLANTEAMIENTO ANALÍtico}

La expresión «legitimación» hace referencia a la configuración de los razonamientos que se emplean para explicar y justificar determinadas creencias y comportamientos; un proceso que se sostiene sobre una aparente pretensión de validez racional que debe ser empíricamente comprobable y criticable (Habermas 1973). De esta definición se infiere la estrecha relación existente entre la legitimidad de una situación y el poder que los diversos actores sociales en ella implicados detentan para definirla en términos de justicia o injusticia, bondad o maldad, belleza o fealdad, etc., así como para desacreditar las definiciones desafiantes.

La perspectiva para el análisis de los discursos propuesta por Ernesto Laclau no restringe su ámbito de aplicación a los fenómenos estrictamente lingüísticos, sino que los relaciona con las prácticas sociales que contribuyen a dotar de una determinada identidad a los actores que actúan en una situación determinada, a las relaciones que establecen y a los hechos que producen. La decisión de recurrir a la teoría del discurso de Laclau tiene que ver con sus características distintivas y su perfecta adaptación a los objetivos planteados. Es decir, la propuesta de Laclau, desde sus orígenes, está pensada para analizar expresamente la dimensión política de los fenómenos sociales o, en otras palabras, el carácter ideológico que convierte los discursos en instrumentos al servicio de las estrategias de poder de distintos actores sociales (Laclau 1990, 1996, 1998; Laclau y Mouffe 1985; Laclau y Zac 1994).

Todos los elementos que conforman la realidad social poseen un significado que les ha sido conferido a partir de sistemas interpretativos diferentes. Así, la imagen de una urbanización turística frente al mar puede ser interpretada como una agresión ecológica, el fruto más representativo del desarrollo de una región, la cara más visible de un oscuro entramado de especulaciones inmobiliarias, una imagen asociada al relax vacacional, etc. El significado social que finalmente se imponga acerca de la realidad objetiva «urbanización frente al mar» depende de la fuerza de cada uno de los discursos interpretativos. Los actores sociales interesados en un campo determinado saben que las prácticas objetivas que sucedan en ese campo dependen de la conquista previa de la definición de la situación. En las próximas páginas se aplica la lógica esencial del esquema analítico propuesto por Laclau a partir de la explicación de los conceptos básicos que dan forma a su teoría política del discurso.

La perspectiva analítica de Laclau se asienta sobre el concepto punto nodal, término recogido de la teoría freudiana que, para el autor, hace referencia a la agrupación de varios elementos discursivos bajo un significante privilegiado, o punto de referencia, que pretende condensarlos y bajo el que quedan ocultos (Howarth y Stavrakakis 2000; Laclau 1996). El proceso de construcción de puntos nodales con el fin de fijar el significado de una realidad social determinada recibe el nombre de articulación. Se trata de un intento por cerrar las interpretaciones posibles de una situación en una única formación discur-

EMPIRIA. Revista de Metodología de Ciencias Sociales. N. ${ }^{\circ}$ 21, enero-junio, 2011, pp. 17-38. ISSN: 1139-5737 
siva, con la que se pretende dar una explicación acabada sobre una realidad. Una explicación en la que se argumenta la irrebatible necesidad de entender la realidad de una manera específica. Esa explicación no es fruto exclusivamente de un proceso cognitivo, se trata además de un proceso imbricado en el contexto social y, especialmente, en los intereses de los actores que participan en el sistema de relaciones sociales. Los discursos se convierten de esta manera en instrumentos para el ejercicio del poder. Por supuesto, el éxito de la articulación nunca es total, debido al carácter abierto de la vida social, consecuencia de la infinita creatividad interpretativa de los seres humanos (Laclau y Mouffe 1985).

La auténtica dimensión del proceso de articulación se entiende mejor cuando se pone en relación con la lógica de equivalencia, elemento clave en el modelo analítico. La lógica de equivalencia tiene que ver con la disolución de algunos de los elementos específicos de una serie de discursos que comparten un denominador común. La disolución de los rasgos propios de cada discurso en torno a una formación discursiva más simple, que se limita a acentuar el denominador común (constituido en forma de punto nodal), pretende la adscripción de un mayor número de sectores sociales y, así convertirse en una herramienta política más efectiva (Laclau y Mouffe 1985).

La práctica de la producción discursiva tiene lugar en el seno de diversos sistemas de relaciones. Esos sistemas tienen un carácter esencialmente político que se expresa en su intento por alcanzar posiciones de poder y en la formación de antagonismos sociales. Este concepto alude al proceso por el cual los actores sociales se enfrentan ante la dificultad para definir las situaciones sociales del modo más conveniente para alcanzar sus intereses. A causa de esta dificultad, se procede a construir un enemigo/oponente (Laclau y Mouffe 1985). La participación en los distintos sistemas de relaciones tiene lugar desde diferentes posiciones subjetivas y subjetividades políticas, es decir, desde las diferentes posiciones con las que una persona se identifica en relación a un determinado asunto público y las distintas formas de actuación por medio de las cuales participa en sociedad (Laclau y Mouffe 1985; Laclau y Zac 1994).

Finalmente, de Antonio Gramsci recupera el término hegemonía, que utiliza para explicar situaciones en las que proyectos políticos en competencia, y con fronteras ideológicas difusas, se esfuerzan por producir formaciones discursivas hegemónicas, orientadas a alcanzar una posición de monopolio en la definición de la realidad social. Para lograr este objetivo se intentan consolidar sistemas de significados ordenados a través de puntos nodales, que han de servir de reclamo al mayor número de personas (Laclau 1990, 1996; Laclau y Mouffe 1985). La hegemonía se refiere aquí a la posibilidad que tiene un grupo de imponer sobre el resto una determinada interpretación de la realidad, de las claves que la explican, así como de la bondad o maldad de la misma

Las limitaciones metodológicas de este enfoque tienen que ver, como puede apreciarse, con sus raíces psicoanalíticas y, en consecuencia, con el esfuerzo interpretativo ligado a la necesidad de hacer emerger la estructura ideológica,

EMPIRIA. Revista de Metodología de Ciencias Sociales. N. ${ }^{\circ}$ 21, enero-junio, 2011, pp. 17-38. ISSN: 1139-5737 
históricamente configurada, que se halla oculta bajo la superficie discursiva actual. En todo caso, se ha pensado que su aplicación puede ofrecer nuevos ángulos desde los que entender la dinámica de un proceso de cambio social tan significativo.

\section{ANÁLISIS Y DISCUSIÓN}

El análisis de los datos textuales recopilados permite reconocer dos posiciones ideológicas antagónicas entre los actores sociales legitimadores del proceso y los críticos. A continuación se presenta y analiza la estructura discursiva de esas dos posiciones que, a modo de oposiciones binarias, quedan enfrentadas. Los fragmentos incluidos en los cuadros 2 y 3 cumplen una función demostrativa, de evidencia empírica. Cuanto mayor es el número de fragmentos que apoyan los argumentos explicativos, más válido y fiable es el análisis cualitativo. Las lógicas restricciones de espacio en un artículo de investigación obligan a seleccionar una muestra limitada. Por esta razón, se ha tenido cuidado a la hora de presentar aquellos que realmente expresan el sentido general de las líneas discursivas identificadas.

\section{El discurso del progreso}

El discurso legitimador, cuya estructura argumental se presenta en el cuadro 2 , incluye a aquellos actores sociales que consideran que el turismo ha supuesto un beneficio esencial para la región. Son valorados muy positivamente los efectos del proceso sobre el sistema económico (construcción, industria del mueble, fontanería, electricidad, comestibles, etc.) y también los culturales (cosmopolitismo). Apenas encuentran elementos críticos y los que puedan hallarse se atribuyen a los efectos normales derivados de cualquier proceso de modernización económica, urbanización e incremento de la complejidad sociocultural. Estos actores sociales consideran que las críticas proceden con frecuencia de posiciones nostálgicas que no aportan nada positivo a la sociedad actual. El turismo satisface la demanda legítima de un mercado muy interesante que hay que cuidar mediante la oferta de un producto de calidad a un precio razonable. El futuro está asegurado porque el clima, que es el principal atractor, no va a cambiar y el contexto sociocultural es acogedor. 
Cuadro 2. Estructura de la posición ideológica legitimadora

\begin{tabular}{|c|c|}
\hline $\begin{array}{l}\text { Principales representant } \\
\text { empresarios promotores }\end{array}$ & $\begin{array}{l}\text { Partido Popular y } \\
\text { mobiliarios. }\end{array}$ \\
\hline $\begin{array}{l}\text { 1) Definición del proceso } \\
\text { Fragmentos: } \\
\text { «Cuando existe un volumen de gente que viene atraída por el } \\
\text { turismo todo el pueblo se activa y resulta fundamental para to- } \\
\text { dos los sectores económicos» (concejal del PP). }\end{array}$ & $\begin{array}{l}\text { Objetivo: } \\
\text { Definir el turismo como la } \\
\text { base del desarrollo local y } \\
\text { la producción de riqueza. }\end{array}$ \\
\hline $\begin{array}{l}\text { 2) Valoración de la situación actual } \\
\text { Fragmentos: } \\
\text { «El resultado final es que tenemos unos ingresos y la población } \\
\text { está más contenta, hay más empleo» (concejal del PP). } \\
\text { «Sin lugar a dudas, nos ha beneficiado y hemos alcanzado un } \\
\text { nivel de vida muy alto gracias a las aportaciones del turismo» } \\
\text { (concejal del PP). } \\
\text { «La gente sabe que el turista es el que le da de comer, porque } \\
\text { permite que su negocio funcione» (concejal del PP). }\end{array}$ & $\begin{array}{l}\text { Objetivo: } \\
\text { Establecer una relación de } \\
\text { causalidad incuestionable: } \\
\text { más turismo } \rightarrow \text { más em- } \\
\text { pleo } \rightarrow \text { más ingresos } \rightarrow \\
\text { más felicidad. }\end{array}$ \\
\hline $\begin{array}{l}\text { 3) La base del antagonismo } \\
\text { Fragmentos: } \\
\text { «Lo que estamos creando es una serie de necesidades y de ser- } \\
\text { vicios, focos donde la gente puede buscar un puesto de traba- } \\
\text { jo... Todo eso es lo que está generando una riqueza que es lo } \\
\text { que nos está beneficiando» (empresario promotor). } \\
\text { «La verdad es que hemos crecido y, como dice el alcalde, he- } \\
\text { mos hecho los deberes bien» (concejal del PP). } \\
\text { «Los ecologistas deberían intentar sacar adelante el trabajo del } \\
\text { agricultor, a ver si les parece tan sencillo. Muchos agricultores } \\
\text { reconocen que hay otras alternativas de desarrollo socioeco- } \\
\text { nómico que tienen que ver con el turismo y con un tipo de ur- } \\
\text { banismo planificado y sostenible» (empresario promotor). } \\
\text { «No se puede ser tan desalmado ni tan iluminado como para } \\
\text { pensar que hay que volver a otras cosas» (concejal del PP). }\end{array}$ & $\begin{array}{l}\text { Objetivo: } \\
\text { Identificación de los dos } \\
\text { bandos: } \\
\text { a) reconocimiento entre } \\
\text { nosotros (poder político) y } \\
\text { la gente (mayoría difusa a } \\
\text { la que queda asimilada uno } \\
\text { de los grupos supuesta- } \\
\text { mente más perjudicados: } \\
\text { los agricultores). } \\
\text { b) los ecologistas (y sus se- } \\
\text { guidores). } \\
\text { Deslegitimación del opo- } \\
\text { nente a través de la ridicu- } \\
\text { lización y la inculpación. }\end{array}$ \\
\hline $\begin{array}{l}\text { 4) Propuesta para el futuro } \\
\text { Fragmentos: } \\
\text { «El futuro está en seguir manteniendo lo que hay y en mejo- } \\
\text { rarlo» (concejal del PP). } \\
\text { «Lo que hay que hacer es sacarle rendimiento a la riqueza me- } \\
\text { dioambiental que tenemos y ofertar medio ambiente a la gen- } \\
\text { te que quiera venir. Si se sabe enfocar a nivel turístico, puede } \\
\text { dar un resultado más positivo que negativo» (concejal del PP). } \\
\text { «Nosotros buscamos el turismo residencial, el de las vivien- } \\
\text { das secundarias... Entonces esa es la apuesta que hacemos, la } \\
\text { del turismo de calidad» (concejal PP). }\end{array}$ & $\begin{array}{l}\text { Objetivo: } \\
\text { Establecer una relación in- } \\
\text { cuestionable: } \\
\text { nuestro modelo turístico }= \\
\text { modelo de calidad (basado } \\
\text { en la oferta y la demanda) } \\
\rightarrow \text { el futuro. }\end{array}$ \\
\hline
\end{tabular}

EMPIRIA. Revista de Metodología de Ciencias Sociales. N. ${ }^{\circ}$ 21, enero-junio, 2011, pp. 17-38. ISSN: 1139-5737 
La articulación del discurso legitimador se realiza en torno al término "progreso», que actúa como punto nodal. La idea del «progreso» se constituye en un punto de identificación por medio del cual una serie de significantes superficiales («floating signifiers»), propios de discursos particulares, se agrupan y fijan bajo un término estable. La red de los principales discursos que quedan soterrados, a partir de los cuales se produce la lógica de equivalencia, tiene un origen y propósitos diferentes:

1) Aunque, obviamente, quienes se adscriben al «discurso propagandístico» no tienen porque sentir ninguna identificación con el franquismo, la realidad es que este discurso hunde sus orígenes en la retórica política franquista de los años 60. Su función es publicitaria y tiene como principal objetivo proyectar a los países emisores de un mayor número de turistas (esencialmente el Reino Unido y Alemania) una imagen de la sociedad española caracterizada por la modernidad (económica y cultural).

«Hemos creado riqueza y hemos conseguido sacar a este país de una situación muy mala entre todos. Ahora todo el mundo nos mira. Muchos se asombran de todo lo que ha hecho España. De lo bien que ha sabido encauzar su transformación en un país moderno. Y esto ha sido gracias al turismo» (Empresario promotor).

2) Intensamente ligado al discurso anterior, se identifica un «discurso del crecimiento», que enfatiza la indiscutible necesidad de aumentar año tras año el número de turistas extranjeros que visitan el país. La razón de tal insistencia durante los años 60 era proporcionar cierto equilibrio a un sistema económico precario. En la etapa democrática, este discurso se identifica con la necesidad de sostener la economía de un país cuyo PIB se volvería escuálido sin la producción de riqueza motivada por el turismo y por la actividad constructora a él ligada. Si se puede identificar una instrumentalización ideológica del turismo durante el franquismo, igualmente se puede reconocer una instrumentalización inmobiliaria de la actividad turística durante el periodo democrático (Mazón 2001). Ésta se plasma en un discurso político producido desde los ámbitos políticos y económicos de los municipios turísticos del Mediterráneo. El siguiente fragmento extraído de una de las entrevistas realizadas es ilustrativo:

«Hemos alcanzado un nivel de vida muy alto gracias a las aportaciones del turismo, me refiero a todo lo relacionado con la construcción, la carpintería, las ferreterías, etc., y todo el comercio que vive del turismo» (empresario promotor).

Los dos discursos citados, cuya génesis y dinámica ha sido analizada por Mantecón (2009) a partir del análisis de contenido de noticias periodísticas, reflejan la instrumentalización ideológica y económica de la actividad turística por parte de las autoridades franquistas. Una instrumentalización que encajaba en el contexto de la ideología desarrollista hegemónica en la política española de los

EMPIRIA. Revista de Metodología de Ciencias Sociales. N. ${ }^{\circ}$ 21, enero-junio, 2011, pp. 17-38. ISSN: 1139-5737 
años 60 y principios de los 70 y que ha impregnado nuestra concepción del hecho turístico hasta la actualidad. Estos discursos encuentran su correspondencia en una política orientada al logro de beneficios económicos inmediatos a partir del aumento de la llegada de turistas, en detrimento de la planificación de un desarrollo sostenible y de la adecuación de la demanda a las características específicas de cada región (Monfort e Ivars 2001). Las noticias turísticas de esta época reflejan con vehemencia el interés por incrementar y dar publicidad a la llegada de turistas internacionales y dejan a un lado el hecho de que haya países que superan a España en ingresos turísticos y no en número de visitantes (Mantecón 2009). Al respecto, se indica que en los años 60 se empieza a producir un efecto socioeconómico negativo: el aumento de llegadas de turistas internacionales respecto al año anterior y el descenso de ingresos generado por éstos en relación también con el año precedente.

Se produce una relación de identificación entre la actividad constructora (y las actividades económicas directamente asociadas a ella) y la actividad turística. De esta manera, se confunde el contenido del significante «construcción» con el del significante «turismo». Tanto a los políticos responsables de la gestión municipal como a los empresarios responsables del negocio de la construcción les resulta más fácil desarrollar una estrategia discursiva con pretensiones hegemónicas alrededor de la propuesta de un modelo de desarrollo local basado en el turismo que alrededor de la propuesta de otro basado en la construcción, pues las repercusiones de una y otra actividad son valoradas de modo muy diferente por el conjunto de la ciudadanía, sobre todo en relación con su influencia sobre el patrimonio ecológico, principal capital de estas regiones. Como explica Schriewer (2008: 86): «No puede sorprender que la empresa más grande del sector en Murcia, Polaris World, se presente como la ' $\mathrm{n}$ 1 en turismo residencial' y no como la ' $\mathrm{n}^{\circ} 1$ en inmigración europea'». Así pues, expresiones como «sostenible»o «calidad» se convierten en valores sociales deseables que sirven para identificar los intereses del núcleo que produce los discursos con los intereses generales de la gente. El hecho de que bajo estas palabras tenga lugar una realidad objetiva que no se ajusta al significado socialmente compartido de las expresiones citadas da lugar, en última instancia, a la articulación de un discurso sobre un punto nodal («progreso») que actúa en realidad como un significante vacío, aunque respaldado por la inercia histórica del discurso político desde hace cuatro décadas. La estrategia hegemónica de este discurso se articula en torno a una apariencia de necesidad, a la presentación del modo de desarrollo conocido como el único posible:

«No se puede ser tan desalmado ni tan iluminado como para pensar que hay que volver a otras cosas» (concejal del PP).

Es decir, como el único modo de desarrollo que ha probado su capacidad para garantizar el equilibrio del sistema proporcionando bienestar material a la ciudadanía. De esta manera, los intereses de los productores del discurso son vinculados con los intereses generales de la sociedad.

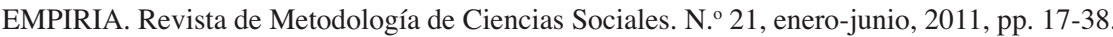
ISSN: $1139-5737$ 


\section{El discurso de la negación y la masificación}

Para la posición ideológica crítica, cuya estructura argumental se presenta en el cuadro 3, el proceso de modernización y cambio social que ha tenido lugar en las regiones turísticas mediterráneas no es una actividad que deba englobarse dentro del ámbito del turismo sino en el de la industria inmobiliaria. De manera más específica, este proceso debería ser considerado como el resultado de una intensa actividad especulativo-urbanística basada en la explotación del territorio. Su principal característica es la brutal agresión medioambiental, que se materializa en la saturación del suelo, el uso abusivo del agua y la pérdida de entornos naturales irrecuperables. Desde esta posición se identifican estafas inmobiliarias constantes que, en ocasiones, atraen a mafias criminales. Los responsables de esta situación serían todos los agentes sociales implicados, incluida la propia ciudadanía que legitima a los responsables políticos que amparan esta situación. Su propuesta es la interrupción inmediata de las dinámicas habituales y su transformación a partir de una nueva concepción de la realidad social y natural, si bien, se reconoce que ahora es demasiado tarde y apenas hay alternativas.

Cuadro 3. Estructura de la posición ideológica crítica

\begin{tabular}{|l|l|}
\hline \multicolumn{2}{|c|}{$\begin{array}{l}\text { Punto nodal: la masificación } \\
\text { verdes y de izquierda con tradición comunista, } \\
\text { algunos expertos académicos y una parte de las } \\
\text { asociaciones de hostelería. }\end{array}$} \\
\hline $\begin{array}{l}\text { 1) Definición del proceso } \\
\text { Fragmentos: } \\
\text { «Lo que ellos llaman turismo, para mí no es turismo» (conce- } \\
\text { jal Izquierda Unida, IU). }\end{array}$ & $\begin{array}{l}\text { Objetivo: } \\
\text { Crítica y negación de la } \\
\text { naturaleza turística del pro- } \\
\text { ceso. }\end{array}$ \\
$\begin{array}{l}\text { «Yo creo que el turismo residencial tiene una entidad distinta» } \\
\text { (profesor universitario). }\end{array}$ & \\
«Esta masificación es el fruto de un desarrollo insostenible, \\
poco premeditado y poco calculado, yo creo que con el único fin \\
de sacar mucho dinero, la especulación inmobiliaria ha sido y \\
sigue siendo el detonante» (concejal de IU). \\
«La historia de esta ciudad es la historia de una estafa inmobi- \\
liaria» (concejal de Izquierda Verde, IV). \\
«Esto no ha sido nunca turismo, simplemente la realidad de- \\
mográfica ha cambiado» (concejal de IV).
\end{tabular}

EMPIRIA. Revista de Metodología de Ciencias Sociales. N. ${ }^{\circ}$ 21, enero-junio, 2011, pp. 17-38. ISSN: 1139-5737 


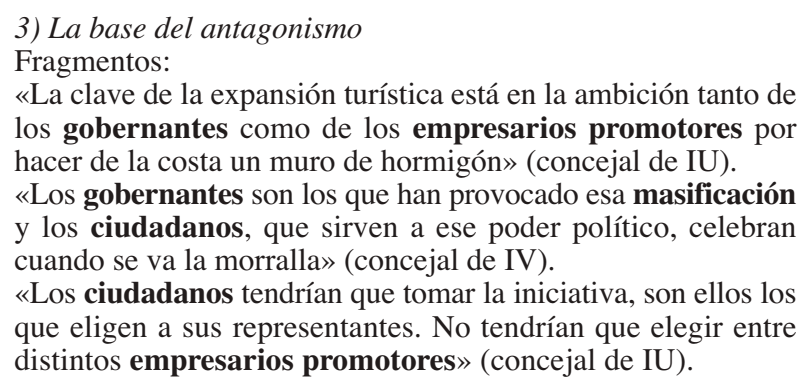

Objetivo:

Identificación de los dos bandos:

a) nosotros (una minoría informada)

b) gobernantes, empresarios promotores y ciudadanos.

Deslegitimar al oponente: Gobernantes y empresarios promotores $=$ intereses económicos privados.

Ciudadanía $=$ irresponsabilidad y desconocimiento.

4) Propuesta para el futuro

Fragmentos:

«Hay que evitar que el mercado regule la actividad consObjetivo:

Transformación social.

tructora» (concejal de IU).

«Como ciudad turística creo que tenemos poco futuro» (concejal de IV).

El punto nodal que sirve para articular el discurso crítico es la expresión «masificación». El término «masificación» es el común denominador de diferentes discursos y se constituye en un punto de identificación bajo el que actúa la lógica de equivalencia, diluyendo las características particulares de diversos proyectos discursivos:

1) En este caso los discursos no tienen una conexión evidente con los años del franquismo, aunque sí vinculaciones indirectas. Se hace alusión específicamente al «discurso de la lucha de clases». La lógica del antagonismo tiene aquí una relación evidente con la tradición ideológica que analiza la realidad social a partir de la distinción entre unas elites capitalistas que controlan los medios de producción y la mayoría de trabajadores que no lo hacen. Los productores de este discurso, normalmente políticos ligados a partidos de orientación comunista (y también algunos expertos universitarios), tratan de desenmascarar y denunciar la naturaleza no turística del proceso de cambio social al que hemos hecho referencia. En su lugar, prefieren redefinirlo como una versión agresiva y perversa del modo de producción capitalista-inmobiliario, controlado por una clase burguesa ad hoc de políticos corruptos y empresarios promotores. Este discurso no tiene una relación inmediata con los procesos de articulación ideológica que tuvieron lugar durante el franquismo. Las transformaciones sociales que acompañaban entonces a las dinámicas turísticas eran consideradas superfluas por los partidos de izquierdas, que, como apunta Mazón (2001), en aquellos años fijaban su atención en otros fenómenos sociales a la hora de poner de manifies-

EMPIRIA. Revista de Metodología de Ciencias Sociales. N. ${ }^{\circ}$ 21, enero-junio, 2011, pp. 17-38. ISSN: $1139-5737$ 
to las contradicciones del sistema. Sin embargo, los partidos de izquierdas con tradición comunista que en la actualidad tienen alguna representación en los gobiernos locales de estas regiones sí que emplean el esquema analítico marxista para formular la crítica al, según ellos, incorrectamente denominado «turismo residencial».

«No es un modelo turístico. Es solamente el resultado de un mercado desregulado y controlado por una serie de grupos político-económicos que están sacando tajada de 'su' negocio inmobiliario» (concejal IU)

2) El «discurso ecologista» representa el pilar más sólido de esta posición y se ha conformado durante las últimas dos décadas. Tiene su origen en las organizaciones no gubernamentales, en los partidos políticos verdes y en la crítica presentada por una parte de los expertos universitarios. De esta manera, esta posición ideológica se sostiene, por un lado, sobre la crítica a la sustitución del «(tradicional) entorno natural» por el «(nuevo) entorno construido» $y$, por otro lado, sobre la denuncia de las «políticas de simulación» (Blühdorn 2004), concepto que hace referencia a prácticas sociales, generalmente circunscritas a la retórica política, cuya función es generar o preservar una ilusión que está en contradicción con el diagnóstico que resulta del análisis empírico de la realidad. Las políticas de simulación se dedicarían a reforzar fachadas en un contexto de escenificación y de una supuesta reconciliación entre dos grupos de prioridades mutuamente excluyentes, como ha podido resultar en este caso la apuesta por un desarrollo sostenible y, al mismo tiempo, por la explotación masiva del mercado inmobiliario. A partir de estas ideas el propio discurso se bifurca en líneas diversas que no aciertan a plantear una estrategia discursiva unitaria, pues los actores sociales que agrupa no han sido capaces de alcanzar un consenso acerca de cómo debe ser criticado el «(nuevo) entorno construido», debido a que la transformación del medio ambiente se ha manifestado de formas muy variables entre unos lugares y otros. Independientemente de este hecho, tampoco se ha alcanzado un acuerdo en relación a los criterios que permitan discernir qué son buenas o malas prácticas ambientales y cuál es en términos operativos el nivel de tolerancia del entorno.

«La propia naturaleza inmobiliaria del proceso, el hecho de que los impactos ambientales sean la consecuencia de dinámicas en las que se fusionan elementos del turismo tradicional con otros de la economía inmobiliaria..., pues todo ello dificulta mucho la identificación de los vínculos existentes entre unas actividades concretas y sus repercusiones. Y en esas estamos. Lo que sí está claro es que este modelo no es sostenible» (concejal IV).

3) El «discurso científico» tiene su origen en la década de 1970 y su momento de eclosión en los últimos diez años, con la proliferación de científicos sociales interesados en estudiar las características de este proceso. El discurso de los expertos (Mantecón 2008a) plantea la necesidad de reconocer la complejidad

EMPIRIA. Revista de Metodología de Ciencias Sociales. N. ${ }^{\circ}$ 21, enero-junio, 2011, pp. 17-38 ISSN: 1139-5737 
de un fenómeno social que, independientemente de tener o no tener una esencia turística, se halla intensamente ligado a fenómenos sociales recientes: aparición de estilos de vida transnacionales, cambios en los mercados inmobiliarios, migraciones internacionales de jubilados, nuevas estrategias residenciales, etc. Así, las dimensiones turísticas del proceso se mezclarían con otras que no tienen un carácter turístico. Aunque se admite la dificultad de discernir las fronteras entre unas dimensiones y otras, se formula una crítica acerca de los problemas de gestión pública asociados a los cambios sociodemográficos, urbanísticos y económicos. A través de la crítica los productores del discurso intentan poner de relevancia la importancia del proceso, al tiempo que exigen su derecho a participar en la gestión del mismo. Se cumple así una de las funciones clásicas ligadas al rol del intelectual (Shils 1972), la del actor social que intenta acceder a las posiciones de poder reclamando el valor de su conocimiento:

«Yo no creo en la previsión política. Los políticos tendrían que rodearse de investigadores que sean capaces de trabajar y de hacer previsiones. Esto no es una utopía. En el Reino Unido o en Estados Unidos los ministros hacen consultas formales a los expertos más reconocidos. Y les hacen caso. A mí me da envidia» (profesor universitario).

Al igual que en el discurso ecologista, también se articula una critica sobre la sustitución de lo «tradicional y auténtico» por lo «nuevo y masificado», en este caso añadiendo a los problemas derivados de la agresión medioambiental otros que están relacionados con la pérdida de la autenticidad cultural, tanto en sus dimensiones arquitectónicas y urbanísticas como en las asociadas a los valores y a los hábitos sociales (Mantecón 2008a).

\section{CONCLUSIONES}

La evolución del llamado turismo residencial ha provocado cambios fundamentales en las regiones mediterráneas españolas. Los estudiosos de este proceso han asumido que las explicaciones se hallan ocultas tras la materialidad del mismo. Por eso la mayoría de las investigaciones han fijado su atención en el análisis del mercado inmobiliario, las características socioeconómicas de los flujos turísticos y la movilidad residencial, los cambios en las estructuras sociodemográficas, etc. Reconociendo la necesidad y la importancia de estos trabajos, aquí se ha propuesto una contribución a la comprensión del proceso a partir del análisis de sus elementos inmateriales. En este sentido, se intenta recuperar el valor central de la cultura no material (valores, ideologías) como factor explicativo.

En este artículo se han identificado y analizado en profundidad las dos posiciones ideológicas antagónicas que actualmente pretenden lograr la hegemonía discursiva en el sistema turístico-residencial. El trabajo de campo realizado a tra-

EMPIRIA. Revista de Metodología de Ciencias Sociales. N. ${ }^{\circ} 21$, enero-junio, 2011, pp. 17-38. ISSN: $1139-5737$ 
vés de la aplicación de las entrevistas en profundidad y los grupos de discusión ha permitido reconocer qué actores sociales se asocian a cada posición. Igualmente, se comprueba que quedan pendientes de vincular una parte considerable de los actores sociales implicados. Se trata de aquellos que en otros estudios cualitativos sobre el contexto ideológico del proceso turístico-residencial se han identificado con posiciones ideológicas intermedias: «posición permisiva» y «crítica parcial legitimadora» (Mantecón 2008a,b). Puede comprobarse que los representantes del PSOE, de los partidos nacionalistas e independientes, de las asociaciones de hostelería y comercio y, también, los ciudadanos entrevistados en los grupos de discusión no aparecen asociados a ninguna de las dos posiciones analizadas. La razón es que los discursos producidos por estos actores sociales tienen como principal característica la ambivalencia valorativa. Algunas veces, y dependiendo de los temas específicos, se aproximan más a una de las posiciones extremas o a la otra.

Ante esta situación, los actores que sí se reconocen ligados a una de las dos posiciones estudiadas se dan cuenta de que existe un amplio abanico de grupos sociales susceptibles de ser cooptados y, así, relegar a la marginalidad a la posición antagonista. No obstante, aunque la posición subjetiva y la subjetividad política de los grupos sociales que producen discursos ambivalentes no se halla adscrita nítidamente a ninguna de las dos posiciones apuntadas, ello no quiere decir que la experiencia de lo acontecido durante los últimos años nos impida plantear una hipótesis acerca de cuál de las dos posiciones ha tenido un mayor éxito en su estrategia de cooptación. De tal manera, si la primera posición defiende la legitimidad del modelo de desarrollo que, en esencia, ha mantenido una lógica de actuación similar desde sus orígenes en los años 60, y la segunda posición comentada pretende producir una crítica a la totalidad de esa lógica de actuación y promulga una transformación del modelo social, entonces parece evidente que la experiencia de los hechos indica el triunfo de la primera posición. La estrategia discursiva de la posición legitimadora se ha mostrado más efectiva que la de la posición crítica para lograr la adscripción más o menos coyuntural de los sectores intermedios (ambivalentes). De otro modo, la realidad material del proceso no habría llegado a manifestarse con tanta intensidad y la resistencia social se habría articulado de modo más evidente y efectivo.

Como se ha expuesto, la mayor efectividad de la estrategia discursiva legitimadora tiene que ver con un modo de articulación sustentado en la configuración de un significante (el progreso) que consigue conectar con la ambivalencia valorativa de la mayoría. Por otra parte, la posición crítica, en lugar de desarrollar una estrategia de identificación con la mayoría, acaba por incluir a ésta en la formación de su antagonista. 


\section{BIBLIOGRAFÍA}

BARKe, M. (1999): «Tourism and Culture in Spain: A Case of Minimal Conflict?», en Robinson, M. y Boniface, P. (eds.) Tourism and Cultural Conflicts, Wallingford, CABI, pp. 247-267.

BlÜHDORN, I. (2004): «Post-Ecologism and the Politics of Simulation», en WissenBURG, M. y Levy, Y. (eds.) Liberal Democracy and the Environment. The End of Environmentalism?, London, Routledge, pp. 35-47.

Callejo, J.; GutiérRez, J. y Viedma, A. (2004): Transformaciones de la demanda turística española: apuntes prácticos, Madrid, Ramón Areces.

CARR, R. (1980): Modern Spain, 1875-1980, Oxford, Oxford University Press.

CASADO, M.A. (1999): «Socio-demographic Impacts of Residential Tourism: a Case Study of Torrevieja, Spain», International Journal of Tourism Research, 1, pp. 223237.

CASADO, M.A. (2006): «Retiring to Spain: An Analysis of Differences among North European Nationals», Journal of Ethnic and Migration Studies, 32(8), pp. 1321-1339.

DEL PINO, J. (2003): «Aproximación sociológica a la vivienda secundaria litoral», Scripta Nova. Revista electrónica de geografía y ciencias sociales, Vol. VII, núm. 146(026). http://www.ub.es/geocrit/sn/sn-146(026).htm

DEL PINO, J. (2009): «Las segundas residencias: permanencia y fugacidad de la experiencia turística», en Latiesa, M., García-Ferrando, M. y Álvarez-Sousa, A. (eds.) Sociología del ocio y del turismo, Granada, Universidad de Granada, pp. 147-166.

GarCíA, H.; Aledo, A. y Ortiz, G. (2010): «Análisis de mapas causales de impactos del turismo residencial», Empiria. Revista de metodología de ciencias sociales, 20, pp. 61-86.

García De Cortázar, F. y González Vesga, J.M. (1993): Breve Historia de España, Madrid, Alianza.

GAVIRIA, M. (1976): El turismo de invierno y el asentamiento de extranjeros en la provincia de Alicante, Alicante, Diputación Provincial.

Gustafson, P. (2001): «Retirement Migration and Transnational Lifestyles», Ageing and Society, 21(4), pp. 371-394.

Gustafson, P. (2008): «Transnationalism in Retirement Migration: The Case of North European Retirees in Spain», Ethnic and Racial Studies, 31(3), pp. 451-475.

GustAFSON, P. (2009): «Your home in Spain: residential strategies in international retirement migration», en Benson, M. y O'ReILly, K. (eds.) Lifestyle Migration: Expectations, Aspirations and Experiences, Aldershot, Ashgate, pp. 69-86.

Habermas, J. (1973): Legitimationsprobleme im Spätkapitalismus, Frankfurt, Suhrkamp Verlag.

Howarth, D. y STAVRaKaKis, Y. (2000): «Introducing discourse theory and political analysis», en Howarth, D., Norval, A.J. y StaVRaKakis, Y. (eds) Discourse theory and political analysis, Manchester, Manchester University Press, pp. 1-23.

Huber, A. y O'ReILly, K. (2004): «The construction of Heimat under conditions of individualised modernity: Swiss and British elderly migrants in Spain», Ageing and Society, 24(3), pp. 327-352.

HUETE, R. (2009): Turistas que llegan para quedarse. Una explicación sociológica sobre la movilidad residencial, Alicante, Universidad de Alicante.

JIMÉNEZ, C.I. (2010): «Transnacionalismo y migraciones: aportaciones desde la teoría de 
Pierre Bourdieu», Empiria. Revista de metodología de ciencias sociales, 20, pp. 1538.

JURDAO, F. (1979): España en venta: compra de suelo por extranjeros y colonización de campesinos en la Costa del Sol, Madrid, Ayuso.

KING, R. (2002): «Towards a New Map of European Migration», International Journal of Population Geography, 8, pp. 89-106.

King, R.; Warnes, A. y Williams, A.M. (2000): Sunset Lives: British Retirement Migration to the Mediterranean, Oxford, Berg.

LaCLAU, E. (1990): New Reflections on the Revolution of Our Time, London, Verso.

LACLAU , E. (1996): Emancipation(s), London, Verso.

LAClAU , E. (1998): «The politics of rhetoric», en Culture and Materiality Conference, University of California, Davis, 23-25 abril.

LAClau , E. y MoufFe, Ch. (1985): Hegemony and Socialist Strategy, London, Verso.

LACLAU , E. y ZAC, L. (1994): «Minding the gap: the subject of politics», en LACLAU, E. (ed) The Making of Political Identities, London, Verso, pp. 11-39.

MANTECón, A. (2008a): La experiencia del turismo. Un estudio sociológico sobre el proceso turístico-residencial, Barcelona, Icaria.

MANTECón, A. (2008b): «Procesos de urbanización turística. Aproximación cualitativa al contexto ideológico», Papers. Revista de Sociología, 89, pp. 127-144.

MANTECÓN, A. (2009): «El turismo como noticia. Aproximación al discurso periodístico entre 1960 y 2000», en Latiesa, M., García Ferrando, M. y Álvarez SousA, A. (eds.) Sociología del ocio y del turismo, Granada, Universidad de Granada, pp. 211-228.

Marshall, C. y Rossman, G.B. (1999): Designing Qualitative Research, Thousand Oaks, Sage.

Mazón, T. (2001): Sociología del turismo, Madrid, Ramón Areces.

MAZÓN , T. (2006): «El turismo litoral mediterráneo: ¿políticas turísticas o desarrollo inmobiliario?», en RoDRíGUEZ, J.A. (ed.) Sociología para el futuro, Barcelona, Icaria, pp. 301-310.

MONFORT, V.M. e IVARS, J.A. (2001): «Towards a sustained competitiveness of Spanish Tourism», en Apostolopoulos, Y., Loukissas, Ph. y LeOnTIDOU, L. (eds.) Mediterranean Tourism, London, Routledge, pp. 17-38.

OOA - Observatorio Ocupacional de Alicante (2006): Mercado de trabajo de la provincia de Alicante 2006, Ministerio de Trabajo y Asuntos Sociales e INEM (ed. en cd-rom).

O'REILly, K. (2000): The British on the Costa del Sol. Transnational identities and local communities, London, Routledge.

O'REILlY , K. (2003): «When is a Tourist? The articulation of tourism and migration in Spain's Costa del Sol», Tourist Studies, 3(3), pp. 301-317.

O’REILLY , K. (2007b): «Intra-European Migration and the Mobility-Enclosure Dialectic», Sociology, 41(2), pp. 277-293.

O'REILly , K. y BENSON, M. (2009): «Lifestyle Migration: Escaping to the Good Life?», en Benson, M. y O'ReILly, K. (eds.) Lifestyle Migration: Expectations, Aspirations and Experiences, Aldershot, Ashgate, pp. 1-13

OSE - Observatorio de la Sostenibilidad en España (2006): Cambios de ocupación del suelo en España, Madrid, Ministerio de Fomento.

OVV - Observatorio Valenciano de la Vivienda (2007): Segunda residencia y turismo residencial en la Comunitat Valenciana, Valencia, Conselleria de Medi Ambient, Aigua, Urbanismo i Habitatge.

EMPIRIA. Revista de Metodología de Ciencias Sociales. N. ${ }^{\circ}$ 21, enero-junio, 2011, pp. 17-38 ISSN: 1139-5737 
PACK, S.D. (2006): Tourism and Dictatorship. Europe's Peaceful Invasion of Franco's Spain, Gordonsville, Palgrave.

Pedro, A. (2006): «Urbanization and Second-Home Tourism», en Buhalis, D. y Costa, C. (eds.) Tourism Futures. Tourism Business Frontiers: consumers, products and industry, Oxford, Elsevier, pp. 85-93.

REQUEJO, J (2007): «Turistas: del concepto legal a la compleja realidad del actual panorama español», Estudios Turísticos, 172-173, pp. 147-156.

Rodríguez, V.; FERnÁNDEZ-MAYORALAS, G. y RoJo, F. (2004): «International Retirement Migration: Retired Europeans Living on the Costa del Sol, Spain», Population Re view, 43(1), pp. 1-36.

Roldán LóPEZ, S. y GARCía Delgado, J.L. (1973): «Los nuevos mecanismos de equilibrio de la economía española con el exterior», en FraGA, M., Velarde, J. y DEL CAMPO, S. (eds.) La España de los 70. Vol. II. La economía, Madrid, Moneda y Crédito, pp. 833-858.

SANDELOWSKI, M. (1995): «Qualitative Analysis: What It Is and How to Begin», Research in Nursing \& Health, 18, pp. 371-375.

SautTer, E.T. y Leisen, B. (1999): «Managing Stakeholders. A Tourism Planning Model», Annals of Tourism Research, 26(2), pp. 312-328.

SCHRIEWER, K. (2008): «Los norteuropeos residentes en España vistos por los españoles», en GARcía, M. y Schriewer, K. (eds.): Ni turistas ni migrantes. Movilidad residencial europea en España, Murcia, Isabor, pp. 71-88.

SCHRIEWER, K. y GARCíA, M. (2005): «Entre europeos. Acerca de una posible conciencia europea. El caso de los residentes europeos en España», en FERNÁNDEZ-RUFETE, J. y GARcía, M. (eds.) Movimientos migratorios contemporáneos, Murcia, UCAM, pp. 181-204.

SHILS, E. (1972): The Intellectual and the Power and Other Essays, Chicago, University of Chicago Press.

VERA, F. (1987): Turismo y urbanización en el litoral alicantino, Alicante, Instituto Gil-Albert

VERA, F. (2005): «El auge de la función residencial en destinos turísticos del litoral mediterráneo», Papers de Turisme, 37/38, pp. 95-114.

Vera, F. e IVARS, J.A. (2003): «Measuring Sustainability in a Mass Tourist Destination: Pressures, Perceptions and Policy Responses in Torrevieja, Spain», Journal of Sustainable Tourism, 11(2\&3), pp. 181-203.

\section{RESUMEN}

La evolución del turismo residencial ha provocado cambios fundamentales en las regiones mediterráneas. Los estudiosos de este proceso han fijado su atención en los aspectos relacionados con la cultura material y la estructura social. Por eso, son mayoría las investigaciones que hacen hincapié en el análisis de las dinámicas urbanísticas, los perfiles socioeconómicos de los turistas y los protagonistas de los distintos tipos de movilidad residencial, los impactos ecológicos o los cambios en las estructuras demográficas. Reconociendo la necesidad y la importancia de estos trabajos, aquí se propone recuperar el valor central de la cultura no material como factor explicativo. A partir de la teoría política del

EMPIRIA. Revista de Metodología de Ciencias Sociales. N. ${ }^{\circ}$ 21, enero-junio, 2011, pp. 17-38. ISSN: 1139-5737 
discurso de E. Laclau, se identifican y analizan las características de las principales posiciones ideológicas que actualmente compiten por conseguir una posición de hegemonía en el sistema turístico-residencial que se articula en las sociedades mediterráneas. El trabajo de campo realizado a través de la aplicación de 37 entrevistas en profundidad y 6 grupos de discusión permite reconocer qué actores sociales se asocian a las posiciones más enconadas y cuál es la lógica de actuación de cada una.

\title{
PALABRAS CLAVE
}

Turismo, modernización, hegemonía, ideología, legitimación.

\begin{abstract}
The development of residential tourism has brought about fundamental changes in the Mediterranean regions. Researchers have focused their attention on the aspects related to the material culture and the social structure. Therefore, most of the research emphasises the analysis of urban dynamics, the socioeconomic profile of the tourists and the protagonists of the different types of residential mobility, the ecological impacts, or the changes in the demographic structures. We acknowledge the necessity and importance of this research, but would like to regain the central value of non-material culture as an explanatory factor. Following E. Laclau's political theory of discourse, we identify and analyse the characteristics of the main ideological stances that are nowadays competing to achieve a hegemonic position in the residential-tourism system of Mediterranean societies. Our fieldwork, based on 37 in-depth interviews and 6 focus groups, allowed us to identify which social actors are associated with the most vehement viewpoints and what is the logic behind these.
\end{abstract}

\section{KEYWORDS:}

Tourism, modernisation, hegemony, ideology, legitimation 